\title{
Engineering Education Research and Development at Queen's University
}

Research and development in engineering education has been prominent at Queen's University since the early 1990's. Initially focused on evolving improved methods to encompass theoretical, practical, industrial, and multidisciplinary aspects into undergraduate engineering programs, the outcome of those early endeavours became what is now known as "Integrated Learning" at Queen's. This effort also recognized the need for a new and different facility to accommodate evolving pedagogical approaches and enhanced team-based activities, and in 2005, the 6,000 $\mathrm{m}^{2}$ Integrated Learning Centre was opened. Both the Integrated Learning philosophy and the corresponding facility have been a tremendous success.

With the establishment of Integrated Learning, engineering education research began to expand both in breadth and depth. Research studies and publications have included topics such as optimized assessment of both students and pedagogical activities, understanding student attitudes towards learning, evaluating engineering practitioners' needs and expectations of engineering graduates, defining needs for outreach activities, developing and assessing measurements for graduate attributes, and using web-based classroom response systems for quality student feedback. Graduate students have been engaged in engineering education research topics for nearly a decade, with the first Master's student with a fullfledged engineering education research topic graduating in 2006, and the first post-doctoral researcher hired in 2011. Additional graduate students have been engaged in engineering education research since, producing four more Master's graduates to date, and two more in process.

The outcomes from this research, combined with collaborative efforts across the faculty, have resulted in new and innovative pedagogy, including the Multidisciplinary Design Stream and the recently introduced Engineering Design \& Professional Practice sequence. Both of these programs include a combination of proven and innovative pedagogy, and through multiple assessment techniques, themselves become the subject of ongoing research and development.

Further research studies are underway. One is exploring how critical thinking develops in first year engineering, and whether the use of complex authentic engineering problems assists in developing critical thinking. Queen's is also part of a learning outcomes consortium project with Toronto, Guelph, and University of Kansas, and three Ontario colleges, to develop procedures for assessing learning outcomes at an institutional level. In addition, Queen's is part of a collaboration with 7 Canadian and US schools on research into sustaining change in institutions and influencing adoption of evidence-based practices.

The panel presentation will provide more detail on our past, present, and future research in this field. The engineering education research community in Canada is dynamic but under-represented, and it is hoped that this session will encourage more engineering academics to venture into this field. 